\title{
Heather's poetic touch alive in our memory
}

\section{Antonio Strati}

To cite this article: Antonio Strati (2017) Heather's poetic touch alive in our memory, Culture and Organization, 23:2, 149-156, DOI: 10.1080/14759551.2016.1170833

To link to this article: http://dx.doi.org/10.1080/14759551.2016.1170833

曲 Published online: 25 Apr 2016.

Submit your article to this journal $\pi$

III Article views: 30

Q View related articles ¿

View Crossmark data \lceil 


\title{
Heather's poetic touch
} alive in our memory

\section{THREE PHOTOPOEMS FOR A PHOTOESSAY}

\author{
Antonio Strati* \\ Research Unit on Communication, Organizational Learning, and Aesthetics (RUCOLA), \\ University of Trento, Italy, and i3-CRG, Ecole polytechnique, CNRS, University Paris- \\ Saclay, France \\ (Received 13 January 2016; accepted 22 March 2016)
}

*Email: antonio.strati@unitn.it 


\author{
I \\ whether it is \\ the building itself, \\ the display case, \\ what surrounds \\ a picture or, indeed, \\ the concept, \\ there is a need \\ to give attention to \\ what constitutes \\ the frame.
}

A frame not only marks the boundary between inside and outside but also moves forward, has a trajectory.

When Perseus holds up the mirror to the Gorgon, when he holds up

his shining shield, the monster is slain by her reflection,

blinded by reflection, cannot see. The mirror is the speculum

which induces speculation, forces back on themselves the images which appear in the reflection.

What do organisations construct and venerate as the beautiful? Where does the construction arise and what are its consequences?

Management has sometimes described itself as an art rather than a science and has frequently, somewhat pretentiously perhaps, regarded this description as evidence of a superior mode of apprehension.

Höpfl, Heather. 2006. "Frame.” Culture and Organization 12 (1): 13, 14, 22, 14. 


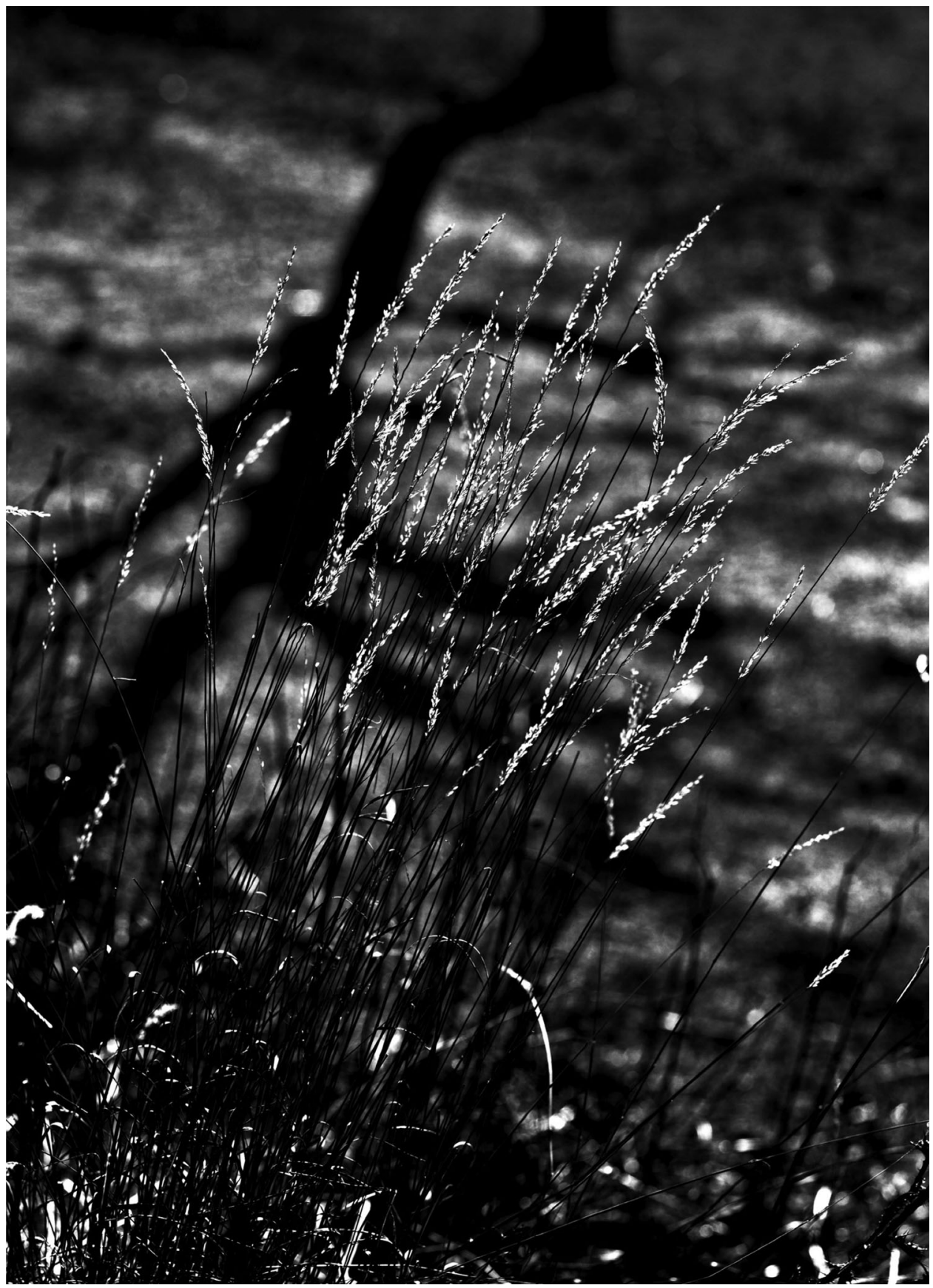

Photopoem I: Poetry as frame. Spike Grass, The Dolomites, Trento, 2015. 


\section{II}

The absence of the school,

the red-brick repository of so many things that I needed to address, was a deprivation.

And, somehow the intensity with which I might have squared my experiences against the building, to have stood face-to-face with it and, I might have hoped, to assign my experiences to its keeping, was left with me.

The school had gone without trace and, contrary to the notion of cleansing or eradication, I found my emotions were homeless.

There is a sense in which my reflections on my inability to consign my assorted memories of my primary school days might be regarded as melancholic.

I am saying that the loss of the physical building in some sense deprived me of a location for feelings which, thus deprived of cathexis, became nebulous and undischarged.

The description stands in relation to the original work and in all its creative richness cannot logically take precedence over

the original and, therefore, is defined in terms of its relationship and captured by that definition.

Thus, variation and imagination are free to work in the process of reproduction but only to the extent that they ensure the perfection of the reproduction as copy.

The aesthetic is always captured within the form.

In other words, creativity is always subordinated to the process of production.

Höpfl, Heather. 2000. "The Aesthetics of Reticence: Collections and Recollections.” In The Aesthetics of Organization, edited by Stephen Linstead and Heather Höpfl, 94, 97, 101, 103. London: Sage. 


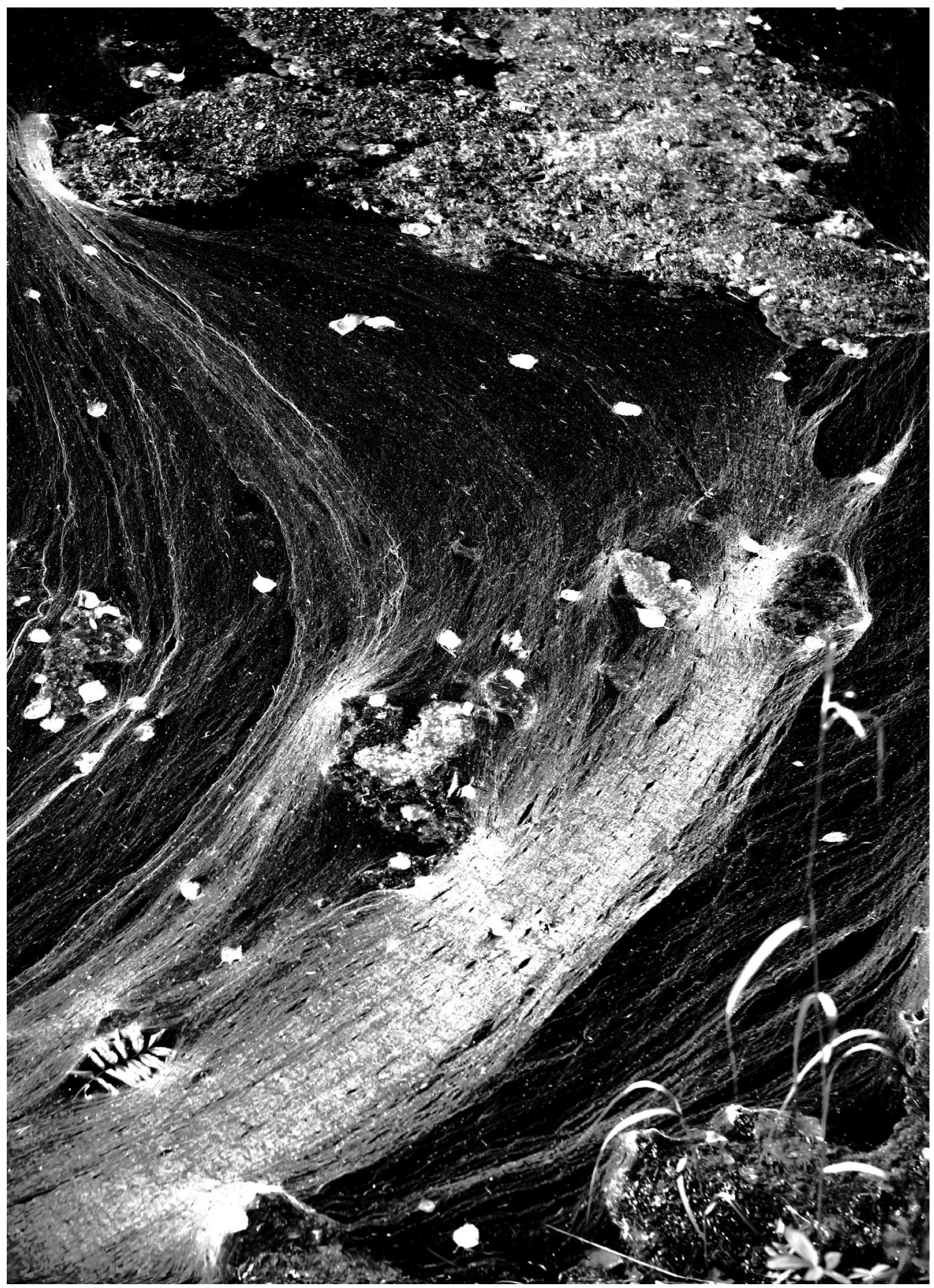

Photopoem II: Poetry as form. Kuusensuopursuruoste (rust of a march Labrador tea of a spruce), Keropirtti, Lapland, 2015. 


\section{III}

The period in which aesthetics has come to prominence has coincided with

an increasing metrification of organizational processes and performance.

It has been a time of performance indicators, targets and metrics

but this has produced

a loss of contact with embodied experience.

... there is an emphasis on the text to the exclusion of the body.

Not surprisingly then the interest in aesthetics can be seen as a resistance to:

- Crude utilitarian theories of organizations and organizational behaviour

- A world reduced to simple statistical measures

- One dimensional accounts of organizational life and simple

$$
\text { 'case-studies' }
$$

- An absence of the senses and embodied experience

- A culture of performance measurement and monitoring

- Matrix structures and other definitional simplicities

- Naive change strategies

- An absence of compassion

- Rationality privileged in theories of organizing

- A view of organizations in which 'people skills' are only relevant to the

extent that they support organizational objectives

- A commitment to continuous improvement which implies a loss of contact

with the moment.

... an aesthetics of organizing

is about finding ways

to remind ourselves of our humanity,

about ways of organizing which sustain the body and cherish the soul.

Höpfl, Heather. 2008. “Aesthetics and Management”. In The Turn to Aesthetics: An Interdisciplinary Exchange of Ideas in Applied and Philosophical Aesthetics, edited by Clive Palmer and David Torevell, 21, 27. Liverpool: Liverpool Hope University Press. 

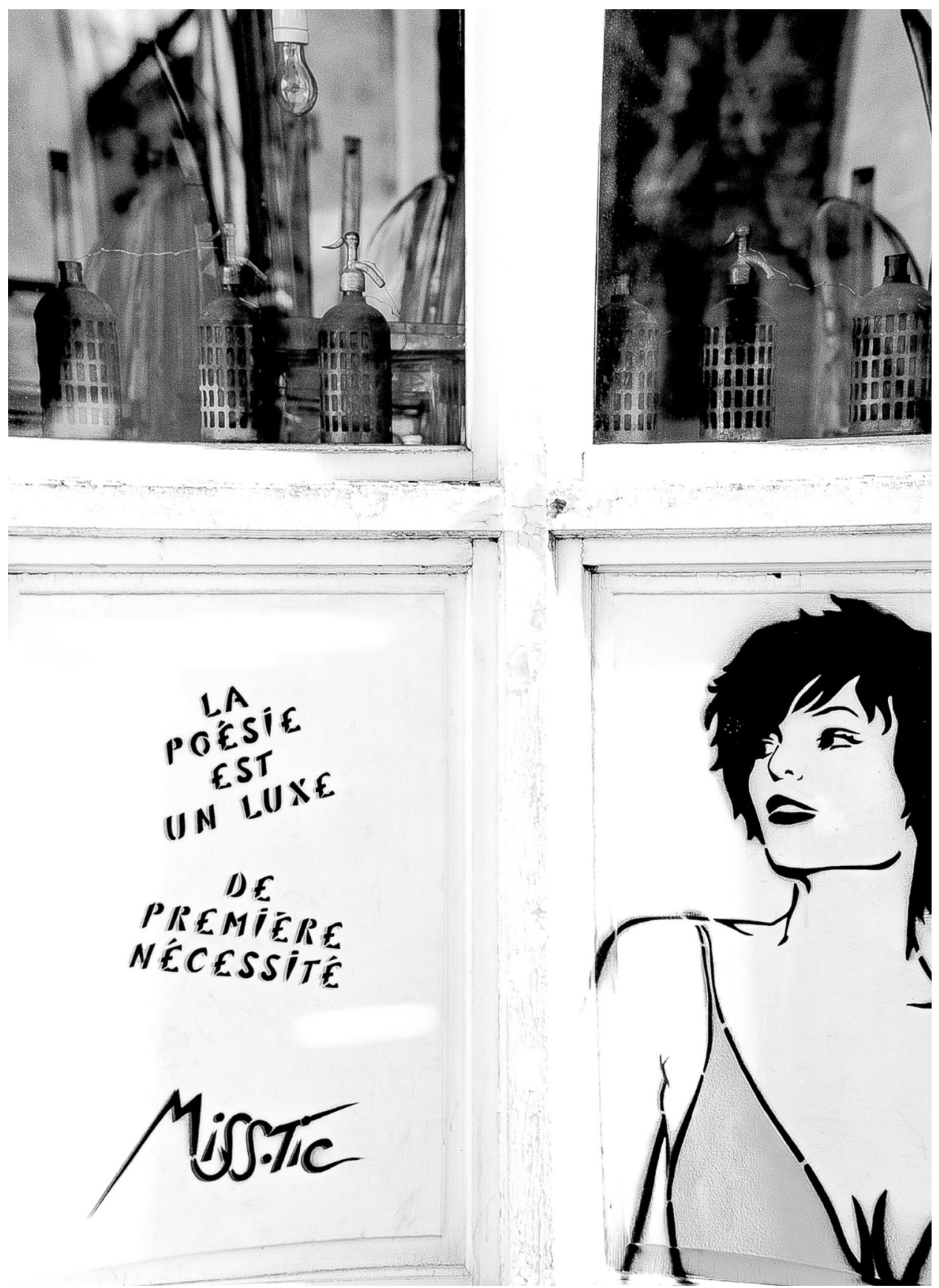

Photopoem III: Poetry as manifesto. The Day After November 13, La Butte aux Cailles, Paris, 2015. 
ORCID

Antonio Strati @ http://orcid.org/0000-0002-1195-8842 